San Jose State University

SJSU ScholarWorks

Master's Theses

Master's Theses and Graduate Research

1994

\title{
Effect of parental divorce on constructive thinking and world assumptions
}

Marilyn Brownton Miles

San Jose State University

Follow this and additional works at: https://scholarworks.sjsu.edu/etd_theses

\section{Recommended Citation}

Miles, Marilyn Brownton, "Effect of parental divorce on constructive thinking and world assumptions" (1994). Master's Theses. 852.

DOI: https://doi.org/10.31979/etd.ntvu-8ke3

https://scholarworks.sjsu.edu/etd_theses/852

This Thesis is brought to you for free and open access by the Master's Theses and Graduate Research at SJSU ScholarWorks. It has been accepted for inclusion in Master's Theses by an authorized administrator of SJSU ScholarWorks. For more information, please contact scholarworks@sjsu.edu. 


\section{INFORMATION TO USERS}

This manuscript has been reproduced from the microfilm master. UMI films the text directly from the original or copy submitted. Thus, some thesis and dissertation copies are in typewriter face, while others may be from any type of computer printer.

The quality of this reproduction is dependent upon the quality of the copy submitted. Broken or indistinct print, colored or poor quality illustrations and photographs, print bleedthrough, substandard margins, and improper alignment can adversely affect reproduction.

In the unlikely event that the author did not send UMI a complete manuscript and there are missing pages, these will be noted. Also, if unauthorized copyright material had to be removed, a note will indicate the deletion.

Oversize materials (e.g., maps, drawings, charts) are reproduced by sectioning the original, beginning at the upper left-hand corner and continuing from left to right in equal sections with small overlaps. Each original is also photographed in one exposure and is included in reduced form at the back of the book.

Photographs included in the original manuscript have been reproduced xerographically in this copy. Higher quality $6^{\prime \prime} \times 9^{\prime \prime}$ black and white photographic prints are available for any photographs or illustrations appearing in this copy for an additional charge. Contact UMI directly to order.

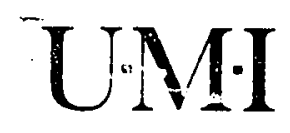

University Microfilms Internatıonal

A Bell \& Howell information Company 300 North Zeeb Road. Ann Arbor, Mi 48106-1346 USA $313 / 761-4700 \quad 800 ; 521-0600$ 
Order Number 1359095

Effect of parental divorce on constructive thinking and world assumptions

Miles, Marilyn Brownton, M.A.

San Jose State University, 1994

Copyright $(\mathcal{C} 1994$ by Miles, Marilyn Brownton. All rights reserved.

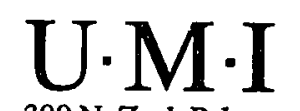

$300 \mathrm{~N}$. Zeeb Rd.

Ann Arbor, MI 48106 



\title{
EFFECT OF PARENTAL DIVORCE ON CONSTRUCTIVE THINKING AND WORLD ASSUMPTIONS
}

\author{
A Thesis \\ Presented to \\ the Faculty of the Department of Psychology \\ San Jose State University \\ In Partial Fulfillment \\ of the Requirements for the Degree \\ Master of Arts
}

by

Marilyn Brownton Miles

August, 1994 
(C) 1994

Marilyn Brownton Miles

ALL RIGHTS RESERVED 

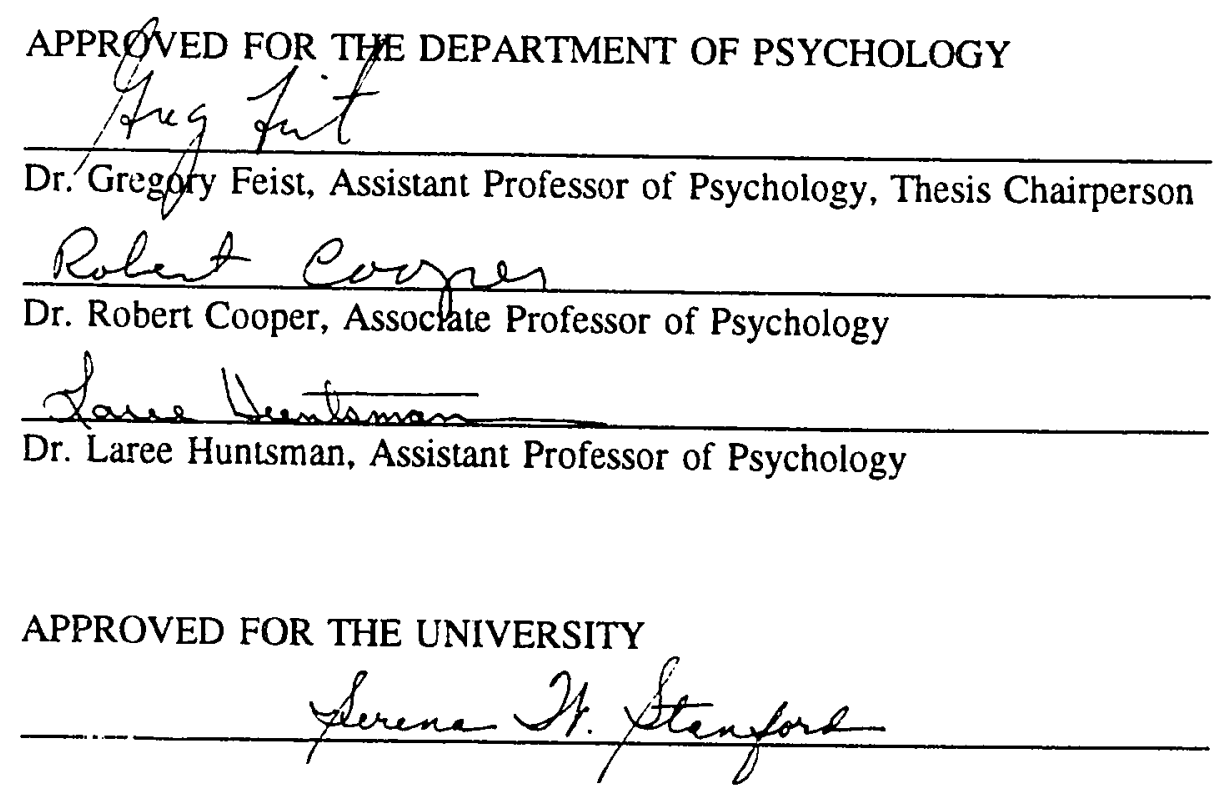


\section{ABSTRACT \\ EFFECT OF PARENTAL DIVORCE ON CONSTRUCTIVE THINKING AND WORLD ASSUMPTIONS}

By Marilyn Brownton Miles

This archival study examines long-term effects of divorce on coping skills and world assumptions of two groups: adults whose parents divorced and adults whose parents remained married. Subjects were students enrolled in upper division Personality and Social Psychology courses who voluntarily completed the Constructive Thinking Inventory (CTI), which measures coping strategies, and World Assumptions Scale (WAS), which measures worldviews. Three hypotheses were examined: (1) children of divorce represent a distinct group compared to children of nondivorce in their coping abilities and worldviews; (2) family status (divorce versus nondivorce) predicts coping styles; and (3) the interaction of gender and age at the time of divorce predicts adult coping strategies and worldviews.

Results failed to support the hypotheses: (1) the CTI and WAS failed to discriminate the groups; (2) family status did not predict coping styles; and (3) the interaction of gender and age at the time of divorce did not predict coping styles or worldviews. Results were discussed in: terms of (a) identifying the critical challenges facing all children, (b) exploring the mechanisms by which children of divorce assimilate the divorce experience with their worldview, and (c) focusing on the variables most crucial to children in the divorce experience. 


\section{ACKNOWLEDGMENTS}

I wish to acknowledge the contributions of Todd E. Bodner, John F. Jacobs, and Vickie Tan, all of whom were members of the research team that conducted the longitudinal study on the nature of subjective well-being that provided the data for the current investigation. I would like to especially acknowledge the efforts of Professor Gregory Feist in providing gentle but persistent guidance to the research team throughout the term of the study and to me throughout the thesis process. I also wish to thank the other members of my thesis committee, Professors Laree Huntsman and Robert Cooper, for their constructive comments.

On a personal note, I wish to thank my children (listed in age order), Mandy, Tammy, and Sadie, for their acceptance of my need to pursue this degree and all the time that endeavor entailed. Frequently the "little kids," Tammy and Sadie, had to fend for themselves while Mandy had to get herself to many of her own activities. To their disappointment (and mine), I missed many field trips, Brownie functions, baseball and soccer games, ski trips, family vacations and the like during the past few years. Along with their disappointment comes joy, I hope, as they recognize, through their experience with me, the limitless possibilities for their own futures.

Lastly, I wish to share credit for completion of this degree with my partner, Jim Straw, whose practical assistance and unwavering support made this accomplishment possible. He lent his computer and word processing expertise to every project I undertook throughout the course of my studies and especially to this 
thesis which reflects his considerable word processing talents. Most importantly, despite the chaos caused by our unique blended family, he kept the family, and particularly me, on track (and fed) while I carried on my studies. 


\section{TABLE OF CONTENTS}

SECTION

PAGE

INTRODUCTION

METHOD

Subjects

Materials

Biographical Inventory $\ldots \ldots \ldots \ldots \ldots \ldots \ldots \ldots \ldots$

Constructive Thinking Inventory $\ldots \ldots \ldots \ldots \ldots \ldots$

World Assumptions Scale $\ldots \ldots \ldots \ldots \ldots \ldots \ldots$

Procedures $\ldots \ldots \ldots \ldots \ldots \ldots \ldots \ldots \ldots \ldots \ldots \ldots \ldots \ldots \ldots$

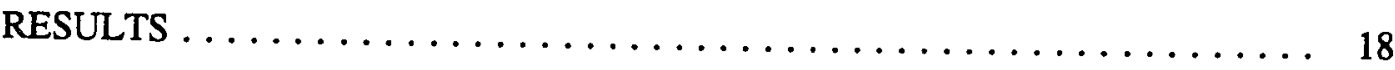

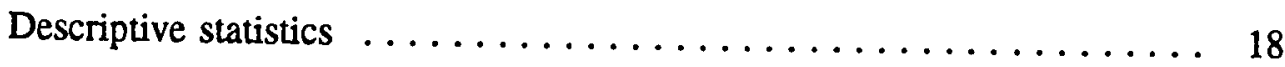

Discriminant Analysis $\ldots \ldots \ldots \ldots \ldots \ldots \ldots \ldots \ldots \ldots \ldots \ldots \ldots \ldots \ldots \ldots$

Hierarchical Multiple Regression Analysis of Four Predictor Variables

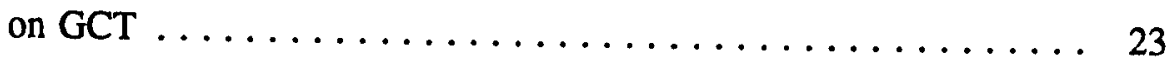

Hierarchical Multiple Regression Analysis of Three Predictor Variables

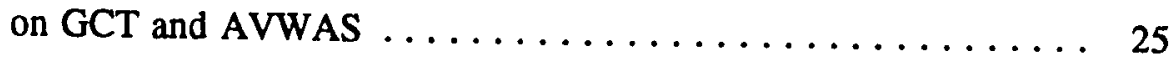

DISCUSSION . . . . . . . . . . . . . . . . . . . . . . . . 29

REFERENCES $\ldots \ldots \ldots \ldots \ldots \ldots \ldots \ldots \ldots \ldots \ldots \ldots \ldots \ldots$

APPENDICES $\ldots \ldots \ldots \ldots \ldots \ldots \ldots \ldots \ldots \ldots \ldots \ldots \ldots \ldots \ldots \ldots$

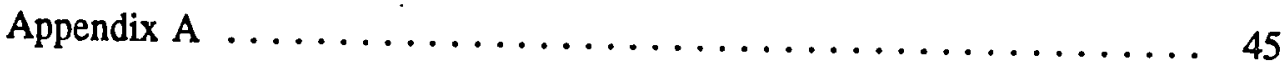




\section{TABLE OF CONTENTS}

SECTION

PAGE

Appendix B $\ldots \ldots \ldots \ldots \ldots \ldots \ldots \ldots \ldots \ldots \ldots \ldots \ldots \ldots \ldots$

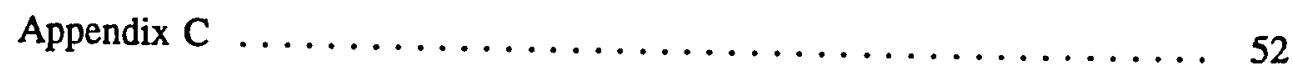




\section{LIST OF TABLES}

TABLE

PAGE

1. Interrcorrelations of WAS Scale Scores at Two Time Periods

2. Descriptive Statistics for All Psychological Variables By Family Status

3. Results of Discriminant Function Analysis of the CTI and WAS

4. Classification Results of the CTI and WAS

5. Interrcorrelations and Regression Results of Four Predictor Variables on GCT Using Hierarchical Method

6. Interrcorrelations and Regression Results of Three Predictor Variables on Criterion Variable GCT Using Hierarchical Method for Divorced Subjects Only

7. Interrcorrelations and Regression Results of Three Predictor Variables on Criterion Variable AVWAS Using Hierarchical Method for Divorced Subjects Only 


\title{
Effect of Parental Divorce on Constructive Thinking and World Assumptions
}

Marilyn Brownton Miles

San Jose State University

\author{
Gregory Feist, Thesis Chairperson
}

San Jose State University

\section{Running Head: EFFECT OF PARENTAL DIVORCE}

\author{
Footnote \\ Request for reprints should be sent to Marilyn Miles, Department of Psychology, \\ San Jose State University, San Jose, CA 95152
}


Effect of Parental Divorce

\begin{abstract}
This archival study examines long-term effects of divorce on coping skills and world assumptions of two groups: adults whose parents divorced and adults whose parents remained married. Subjects were students enrolled in upper division Personality and Social Psychology courses who voluntarily completed the Constructive Thinking Inventory (CTI), which measures coping strategies, and World Assumptions Scale (WAS), which measures worldviews. Three hypotheses were examined: (1) children of divorce represent a distinct group compared to children of nondivorce in their coping abilities and worldviews; (2) family status (divorce versus nondivorce) predicts coping styles; and (3) the interaction of gender and age at the time of divorce predicts adult coping strategies and worldviews. Results failed to support the hypotheses: (1) the CTI and WAS failed to discriminate the groups; (2) family status did not predict coping styles; and (3) the interaction of gender and age at the time of divorce did not predict coping styles or worldviews. Results were discussed in terms of (a) identifying the critical challenges facing all children, (b) exploring the mechanisms by which children of divorce assimilate the divorce experience with their worldview, and (c) focusing on the variables most crucial to children in the divorce experience.
\end{abstract}


Effect of Parental Divorce

Effect of Family Status on Constructive Thinking and World Assumptions

Few events impact a child's life as dramatically and profoundly as the divorce of his or her parents. Beginning with the family crises that eventually culminate in divorce or, alternately, with the shattering of the perfect, happy family myth at the time the impending divorce is announced, the child faces a series of unexpected and most times unwanted changes in the one area of life the child relies on most to provide the consistency and security the child needs to grow and develop into adulthood--the family structure. Regardless of the age of the child at the time of divorce, the divorce signals fundamental, long-lasting changes in intimate relationships and lifestyle patterns for the child. By adapting to living with only one parent at a time, which often results in the loss of meaningful parental contact with the other parent, the child simultaneously copes with any one or combination of the following: new living conditions, new neighborhoods, new schools, new friends, altered economic conditions, and new and complex stepfamily structures created by the remarriage of the child's parents. These changes challenge the cognitive and emotional resources of children in ways unique to children of divorce (Emery, 1988; Farmer, 1989; Hetherington, 1979; Hodges, 1991; Wallerstein \& Blakeslee, 1989; Wallerstein \& Kelly, 1980). Children of divorce perceive that they are different--that they are somehow children "belonging to a special group" (Wallerstein \& Blakeslee, 1989, p. 23) who incorporate their 
child-of-divorce status as an integral part of their self-definition and identity.

The notion that divorce involves a series of traumatic events producing enduring psychological effects on children represents a fairly modern concept. Early research, focusing on the acute and immediate behavioral reactions of children at the time their parents' marriages dissolve, conceived of divorce as a single, brief crisis that within a year or two resolved itself (Wallerstein \& Blakeslee, 1989; Wallerstein \& Kelly, 1980). The seminal work of Wallerstein and Kelly (1980) and Wallerstein and Blakeslee (1989) devastated that simplistic appraisal of divorce when they presented the findings of their longitudinal study of children of divorce. Beginning in 1971, Wallerstein began what eventually culminated in a 5, 10, and 15 year follow-up investigation into the effects of divorce on children. Wallerstein's research represented the first attempt to evaluate empirically the long-term effects of divorce on children. The results (Wallerstein \& Blakeslee, 1989; Wallerstein \& Kelly, 1980) startled the mental health professionals of the time: at the ten-year mark, almost one-half of the children continued to display divorce-related effects and the majority of participantis believed their parents' divorce overshadowed their childhood and unalterably changed their perspectives on life. Despite serious methodological problems with Wallerstein's research, in particular the lack of a control group, Wallerstein's study nonetheless altered the way that theorists and researchers viewed divorce. Most researchers and theoreticians now agiéc that the ureaking of the marriage bond, with the concomitant 
changes in family structure, relationships, and lifestyle, reverberates throughout the life of the child and reformats the child's tasks at each developmental stage--from infancy (approximately birth to 18 months) through toddlerhood (approximately two to four years of age), into the preschool years (approximately three to five years of age), through the middle school years (approximately six to 11 years of age), and ending at adolescence (approximately 12 to 18 years of age) (Cantor \& Drake, 1983; ClarkeStewart \& Friedman, 1987; Emery, 1988; Farmer, 1989; Hetherington, 1979; Hetherington, Stanley-Hagan, \& Anderson, 1989; Hodges, 1991; Kurdek \& Berg, 1987; Oppawsky, 1989).

As an example of how the divorce experience might affect the normal development of children based on Erickson's eight-stage developmental process, Farmer (1989) delineated the altered tasks for children of divorce at every developmental stage. For instance, during the first 18 months of life, the infant's primary task is to form gradually a lifelong trusting relationship with the world, beginning with the recognition that the self represents an entity separate from other people and objects and includes the development of a reliable system of communication whereby the physical and emotional needs of the infant are met. Because the infant relies on sensory experience as the primary source of information, the tension occasioned by marital disruptions experienced by primary caretakers becomes transmitted to the infant despite verbal assurances that "everything will be all 
right" (Farmer, 1989, p. 261). Moreover, the primary caretakers' preoccupation with the marital crises and the concomitant details of structuring a new life creates an environment where the infant receives less attention to the satisfaction of his or her needs. The combined effects, rather than creating a secure base from which the infant explores the environment, disrupt the normal developmental progression of the infant by introducing anxiety in the infant's relationship with the world--an anxiety that the infant must surmount or somehow incorporate into a worldview that allows the infant to continue on the developmental path. How successfully the infant masters this additional hurdle necessarily affects the next and succeeding developmental stages.

As another example, later on, in adolescence (approximately 12 to 18 years of age), children's primary task is to individuate and establish their own identity, assuming responsibility for their own personal life management as they move into adulthood and away from the family as their main source of structure and authority. If, as a result of family crises occasioned by the divorce, teenagers' attention turns back to the family and/or if the distracted parents cannot cope with the inevitable conflict that accompanies the emerging identities of their teenager children, then the developmental tasks of adolescence may be retarded or at least made more difficult to master.

Wallerstein and Blakeslee (1989) identified seven psychological issues to be resolved by children of divorce in addition to the normal developmental tasks all 
children face: (1) understanding the divorce, i.e., initially differentiating fact from fantasy in determining what the realistic consequences of the divorce are and later making sense of the divorce in more existential terms useful to the child's worldview; (2) strategic withdrawal, i.e., remaining appropriately concerned and involved with the family issues but removed enough to continue on with age appropriate activities and pursuits; (3) dealing with loss, i.e., untangling the connection between the loss of the family and often the relationship with one parent from feelings of rejection, humiliation, unlovability and powerlessness, all of which affect self-esteem; (4) dealing with anger, i.e., accepting their feelings of anger at their parents for causing them unhappiness while simultaneously recognizing their parents as human and imperfect; (5) working out guilt, i.e., releasing causal responsibility for the divorce and the consequential problems; (6) accepting the permanence of the divorce, i.e., unlike death, divorce could be undone but children must accept the irreversibility of the divorce decision; and (7) taking a chance on love, i.e., accepting the possibility of either failure or success in relationships based on a belief in their own lovability and ability to love.

Despite agreement that divorce engenders long-lasting effects, the literature provides little consensus beyond that. Only two robust findings stand out in the literature: (1) children of divorce feel angry and tend to externalize their reaction to the divorce by exhibiting aggressive, angry behavior, such as explosive temper tantrums, verbal attacks on parents, in particular the father, antisocial behavior at 
school, delinquent behavior, including arson, vandalism, drug involvement and alcoholism, problems at school, including poor learning, truancy and dropping out, and precocious sexual activity and promiscuity (Emery, 1988; Hetherington, 1979; Wallerstein \& Blakeslee, 1989; Wallerstein \& Kelly, 1980); and (2) male children of divorce experience more divorce-related adjustment problems than do female children, both in the immediate and long term, such as intense, unresolved anger at parents, especially the father, more delinquent, antisocial behavior, more difficulty handling problems as an adult and less interest in parenting (Cantor \& Drake, 1983; Heath \& MacKinnon, 1988; Hetherington, 1979; Spigelman \& Spigelman, 1991). Several explanations for these gender differences exist: (1) Cantor and Drake (1983) speculate that because boys do not receive as much positive reinforcement for compliance as do girls they come to rely on negative behavior as their source of attention; (2) Heath and Mackinnon (1988) found, among other things, that for males higher levels of parental acceptance, firm control, higher levels of maternal education, and lower levels of psychological control predicted better social adjustment. Because the majority of single-parented families are headed up by women, many boys from divorced households do not receive the acceptance or the firm control that is typically provided by the male parental figure; and (3) Spigelman and Spigelman (1991) suggest that boys suffer more stress as a result of the divorce experience because they receive less support in working through their emotional turmoil (i.e., big boys don't cry) and thus 
become emotionally isolated. The literature otherwise offers inconsistent, contradictory and confusing research findings that makes meaningful interpretation of divorce related effects difficult.

Some of these inconsistencies can be explained by methodological problems that plague the empirical findings in the literature on divorce-related effects on children (Cantor \& Drake, 1983; Emery, 1988; Levin, 1989). Researchers studying divorce tend to base their findings on small, unrepresentative sample sizes, typically drawing their research pool from clinical and/or self-selected populations. Rarely do researchers use a control group, as for example was the case in the Wallerstein studies. Experimental designs fail to control for the influence of other variables, such as the number of reconciliations, amount and quality of visitation with the noncustodial parent, the abandonment by the noncustodial parent, the type of postmarital interactions and quality of ongoing relationship between the parents, the parents' mental health and quality of parenting style, and the economic condition of the newformed family, and frequently confound the three crucial temporal variables of interest: (1) the age of the child at the time of marital dissolution; (2) the amount of time since the divorce; and (3) the current age of the child. Few studies minimize the influence of the three temporal variables by comparing the adjustment of adults who experienced a parental divorce with those who did not (Emery, 1988).

At the conceptual level controversy among researchers surrounds what 
constitutes the construct of "healthy" functioning and how that construct is to be measured. Some researchers use academic performance as a measure of adjustment while others use peer relationships. No measure of overall adjustment exists to evaluate children of divorce and their ability to cope with life. Moreover, many studies project long-term adjustment based on more immediate divorce engendered effects despite Wallerstein and Blakeslee's (1989) observation that "One cannot predict long-term effects of divorce on children from how they react at the outset" (p. 15). At the empirical level, other than assessments of intellectual and academic performance, few reliable and valid measures of theoretically sound constructs exist.

By improving the methodology used in previous research, the current investigation will attempt to present unbiased results. First, the results are based on a relatively large sample. Secondly, by comparing adults who experienced divorce as children to adults who did not experience divorce as children, the study employs a control group. Thirdly, by using adult subjects and concentrating on long-term effects, the confounding of the three temporal variables noted above (age of the child at the time of divorce, amount of time since the divorce, and current age) becomes less significant because the passage of time moderates the influence of all three temporal variables. Most importantly, this study focused on two theoretically sound constructs, evaluated by reliable and valid instruments--everyday coping strategies, as measured by the Constructive Thinking Inventory (Epstein \& Meier, 1989) and fundamental 
beliefs about how the world operates, as measured by the World Assumptions Scale (Janoff-Bulman, 1989).

Constructive thinking represents a broad coping factor, sometimes referred to as practical intelligence, that exists independently of intellectual ability. An individual's constructive thinking reflects the way in which that individual solves everyday problems based on automatic destructive and constructive thought processes occurring at the preconscious level. Epstein (1990) defined constructive thought processes as "automatic thinking that facilitates coping with problems in living in a manner that maximizes the likelihood of an effective solution at a minimum of cost in stress to oneself and others" (p. 174) as contrasted with destructive thinking "that results in a relatively high cost in stress to oneself and others, relative to the adequacy of the solutions achieved" (p. 174). According to Epstein and colleagues (Epstein, 1990, 1992a, 1992b; Epstein \& Meier, 1989; Katz \& Epstein, 1991), constructive thinking is reflective of the experiential system, which is holistic in nature, non-rational and oriented to learning based on immediate experiences with life.

World assumptions represent the implicit beliefs people hold about how the world operates and how they perceive themselves in relation to the world. JanoffBulman (1989) claims that people possess, to a greater or lesser extent, three fundamental assumptions about the world and themselves: (1) that the world is benevolent, i.e., the world is good and kind; (2) that the world is meaningful, i.e., the 
world is just, rational and has a purpose; and (3) that the self is worthy, i.e., that one is a moral, decent person deserving of good fortune.

Given that divorce symbolizes a chain of stressful life events and given that those traumatic events occasioned by the divorce challenge the ability of a child to develop adequate coping skills, then the CTI and World Assumptions Scale (WAS) seem conceptually and empirically suited to evaluate long-term divorce related effects. Based on the CTI and WAS, the current investigation addressed the following questions and tested the respective hypotheses:

(1) Do adult children of divorce as a group differ from adult children of nondivorce on measures of coping abilities and assumptive world beliefs? It was hypothesized that children of divorce represent a distinct and unique group compared to children of nondivorce on measures that assess coping styles (the CTI) and assumptions about how the world operates (the WAS).

(2) Is family status (divorce versus nondivorce) a better predictor of constructive thinking than present age or gender? It was hypothesized that family status provides additional predictive power over and above demographic data (current age and gender) and worldviews. In other words, whether adults come from a divorced family or nondivorced family is more predictive of their ability to cope than is their current age, their gender or how they view the world.

(3) Does gender and age at the time of the divorce affect adult coping 
strategies and assumptions about the world? It is hypothesized that the interaction of gender and age at the time of the divorce is more predictive of constructive thinking and worldviews than is gender or age at the time of the divorce alone.

Method

Subjects

Subjects for this study $(\underline{N}=125)$ were students enrolled in upper division Personality and Social Psychology courses at a large state university during the Fall semester of 1992 who, for extra credit, voluntarily participated in a research project on the nature of subjective well-being. As participants in that study, students completed a battery of tests, including the two instruments to be used in this study, and also a demographic (biographic) inventory. The mean age of the sample was 27.41 $(S D=7.83)$, with a median of 24 and a range from 20 to 52 . Most subjects (66\%) came from intact families. Of the subjects coming from divorced homes (34\%), the mean age at the time of divorce was $10(S D=7.9)$, with a median of 8 and a range of 1 to 32. Females (84\%) and Caucasians (72\%) dominated the sample with Catholics (44\%) and Protestants (41\%) representing the two most often reported religious affiliation.

Because many subjects failed to fully complete the CTI and/or the WAS at both times, the use of pairwise missing values and the averaging of the WAS scores at two time periods resulted in a significant decrease in the final number of subjects in 
each analysis.

Materials

Biographical Inventory. The Biographic Inventory (Please see Appendix A) solicited biographical information from subjects regarding such items as age, gender, college major, family status (whether parents' were divorced), ethnicity, religious and political affiliations.

Constructive Thinking Inventory. The Constructive Thinking Inventory (CTI), a 64-item inventory designed by Epstein and Meier (1989), based on Epstein's (1980, 1983, 1990) cognitive-experiential theory of the self (CEST) and related research (Epstein, Holstein, Lipson, \& Huh, 1992), assesses an individual's ability to solve everyday problems and dilemmas (Please see Appendix B). The CTI evaluates an individual's overall coping style, reflective of what Epstein refers to as the experiential system, which is one of three components constituting the self (Epstein, 1980; 1983; 1990; Epstein \& Meier, 1989). Holistic in nature and loosely organized, the experiential system, representing the individual's immediate and non-rational orientation to life, directs the individual's behavior on a daily basis. The CTI is related to a variety of indices of success in everyday life, such as being successful at work, in social relations, in intimate relationships and in remaining emotionally and physically fit (Epstein \& Katz, 1992; Epstein \& Meier, 1989; Katz \& Epstein, 1991), in thinking fewer negative thoughts and taking on more responsibilities with less ill effect 
(Epstein, 1992a), in not overgeneralizing negative thoughts about the self (Epstein, 1992b), and in rating oneself above peers and thinking more highly of oneself than do peers (Hurley, 1989).

The CTI requires subjects to respond to items on a Likert scale ranging from 1 to 5, where "1=Definitely False", "2=Mostly False", "3=Neither False or True", "4=Mostly True", and "5=Definitely True". The subscale of interest in the present study is the Global Constructive Thinking Scale (GCT) which includes items from all five subscales and is a bipolar scale measuring the denial of destructive thinking and the acknowledgement of constructive thinking ( $\alpha$ reliability=.80). The GCT reflects an individual's overall level of constructive thinking. Subjects scoring high on this scale tend to accept themselves and others, interpret events in a positive light, and are realistically optimistic. High scorers do not overgeneralize, do not think more highly of themselves than warranted, nor do they rely on superstition and magical thinking to explain the workings of the world. Low scorers tend to have a negative bias, dwelling on past unpleasant experiences and projecting that worry into the future. Low scorers tend to maintain more negative and self-deprecating views of themselves than others. Lastly, low scorers tend to think categorically, overgeneralizing negative outcomes. World Assumptions Scale. The World Assumptions Scale (Janoff-Bulman, 1989) assesses general world views and consists of three subscales: (1) Meaningfulness of the World (MW); (2) Benevolence of the World (BW); and (3) 
Self-Worth (SW) (Please see Appendix C). The MW subscale measures the degree to which an individual believes that outcomes in the world are rational, are "just" (people get what they deserve and deserve what they get; Lerner, 1980) and are not a result of chance. The BW subscale measures the degree to which an individual believes the world is good and kind. The SW subscale measures the degree to which an individual believes he or she is a decent and moral person, deserving of good fortune. The subscales display moderate internal consistency ( $\alpha$ reliability $=.67$ to .78 ). Feist, Bodner, Jacobs, Miles, \& Tan (1994) report acceptable test-retest reliabilities over a 12 week period: $\mathrm{MW}(\mathrm{r}=.60), \mathrm{BW}(\mathrm{r}=.78)$ and $\mathrm{SW}(\mathrm{r}=.84)$.

Studies of the assumptive world beliefs of people who did and did not experience specific traumatic events in the past established the discriminate validity of the scales by showing that assumptions about the world differed in the expected direction between the two groups (Janoff-Bulman, 1989). Those individuals who experienced some particular trauma viewed the world as less benevolent, less meaningful and the self as more vulnerable to misfortune than those whose life remained unchallenged by stressful life events. Moreover, results indicated that the impact of the stressful life events continued years after the event itself.

As a measure of construct validity, the interrcorrelations of the three scales of the WAS at each of the two time periods are presented in Table 1. Based on the 
Table 1

Intercorrelations of WAS Scale Scores at Two Time Periods $(\mathrm{N}=125)$

\begin{tabular}{cccc}
\hline Scale Score & \multicolumn{3}{c}{ Scale Score } \\
T1 & \multicolumn{3}{c}{ T2 } \\
\hline MW & MW & BW & SW \\
\hline BW & $.59^{*}$ & .16 & .16 \\
SW & .02 & $.75^{*}$ & $.54^{*}$ \\
& .01 & $.62^{*}$ & $.87^{*}$
\end{tabular}

$* \mathrm{p}<.001,2$-tailed.

Note: WAS $=$ World Assumptions Scale; $\mathrm{T} 1=$ Time 1; $\mathrm{T} 2=$ Time 2, three months later; $M W=$ Meaningfulness of the World; $B W=$ Benevolence of the World; $S W=S e l f$ as Worthy. 
significance of the correlations between each scale score and that same scale score at the second time period, an average score for each scale score was calculated. This average scale score was used to represent that WAS subscale score for all analyses employed in this study, designated by an " $\mathrm{A}$ " following the abbreviated title. Because scores on the MW subscale at each time period failed to correlate significantly with scores on the other two subscales of the WAS, it appeared questionable whether the MW subscale indeed was measuring the same world assumption construct as the other two subscales. As a result, MW subscale scores were not included in the calculation of the total average WAS score (AVWAS) used in subsequent analyses. Procedures

The current study used archival data obtained in connection with a longitudinal investigation on the nature of subjective well-being. In the original study, subjects completed, along with the demographic inventory, an initial battery of tests, two of which form the basis of this study: the CTI and the WAS. In addition to the initial test battery, students again completed the WAS three months later as part of the longitudinal study. Students completed the forms at home, which took approximately one hour, and returned them to their instructor within one week. Students received extra credit for their participation in the research project. To insure confidentiality, each form carried only a secret identification code created by the subjects based on the first three letters of their mothers' maiden names and the six digits of their birthdays. 
Results

\section{Descriptive statistics}

Table 2 presents the descriptive statistics of each psychological, nondemographic variable under study, identified by family status.

\section{Discriminant Analysis}

To determine whether children of divorce $(\mathrm{N}=24)$ represent a unique group distinct from children of nondivorce $(\underline{N}=41)$ in their ability to cope with the world as measured by the CTI and in the way they view the world as measured by the three WAS subscales, a discriminant analysis (direct method) was conducted on the data. Table 3 presents the results of the discriminant analysis.

As is evident from the results reported in Table 3, the discriminant function failed to reach statistical significance (Wilks' Lambda $=.99, \mathrm{X}^{2}(4)<1$, n.s., canonical correlation $=.023$ ). Thus, group differences account for only .06 percent of the variance in the discriminant scores based on the CTI and WAS. The hypothesis proposed by this study failed to find support: Children of divorce do not represent a distinct group from children of nondivorce on measures that assess coping strategies and views about how the world operates.

Consistent with the failure of the discriminant function to differentiate the groups, a comparison of the relative rankings of the predictor variables between the pooled-within-group correlations of variables with function and standardized variable 
Table 2

Descriptive Statistics for All Psychological Variables by Family Status

\begin{tabular}{|c|c|c|c|c|c|c|c|}
\hline \multirow[b]{3}{*}{ Measure } & \multirow[b]{3}{*}{ Scale } & \multicolumn{6}{|c|}{ Family Status } \\
\hline & & \multicolumn{3}{|c|}{ Divorced } & \multicolumn{3}{|c|}{ Non-Divorced } \\
\hline & & $\mathbf{N}$ & $\mathbf{M}$ & SD & $\mathbf{N}$ & $\mathbf{M}$ & $\mathrm{SD}$ \\
\hline \multirow[t]{3}{*}{ WAS } & MWA & 25 & 62.04 & 9.15 & 48 & 61.76 & 8.99 \\
\hline & BWA & 27 & 54.28 & 11.10 & 49 & 54.74 & 10.08 \\
\hline & SWA & 27 & 80.31 & 14.14 & 47 & 82.37 & 12.50 \\
\hline CTI & GCT & 38 & 86.58 & 16.06 & 75 & 88.17 & 13.83 \\
\hline
\end{tabular}

Note: WAS=World Assumptions Scale; MWA=Meaningfulness of the World average; $B W A=B e n e v o l e n c e$ of the World average; SWA=Self as Worthy average; $\mathrm{CTI}=$ Constructive Thinking Inventory; GCT=Global Constructive Thinking. 


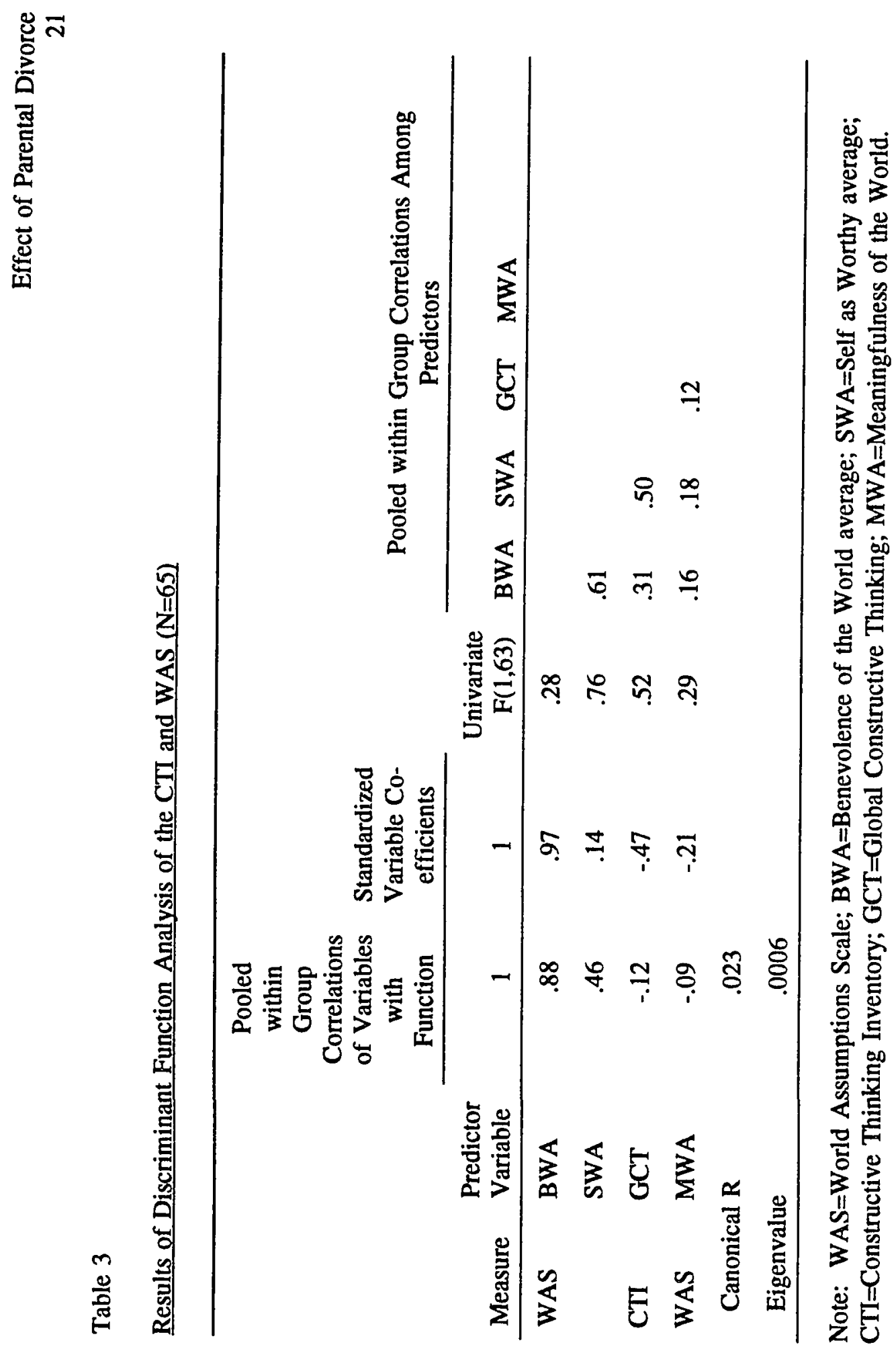


coefficients produces contradictory and uninterpretable results. While BWA consistently ranks first among the predictor variables in both the pooled-within-group correlations of variables with function and the standardarized variable coefficients, the relative rank order of the other predictor variables changes. Thus, the relative importance of the predictor variables in producing the discriminant function (i.e., in discriminating between the groups) cannot be established. A review of the pooledwithin-group correlations among predictors (see Table 3) explains the inconsistency among the relative ranking of the predictor variables. A relatively high degree of interrcorrelation exists between several of the predictor variables, in particular BWA and SWA, BWA and GCT, and SWA and GCT. Multicollinearity of predictor variables creates unstable coefficients as evidenced in this study (Hedderson, 1991; Stevens, 1986).

A review of Table 4 (Classification Results) substantiates the findings noted above. With priors set at 60 percent for subjects whose parents remained married, Group 1, and 40 percent for subjects whose parents divorced, Group 2, (Hetherington, Stanley-Hagan, \& Anderson, 1989; Levin, 1989), the discriminant analysis produced a "hit" rate of 63 percent, that is, the discriminant function correctly identified group membership 63 percent of the time. A closer look at the classification results reveals that the discriminant analysis correctly classified only Group 1 members (subjects from nondivorced families) and misclassified all of Group 2 members (subjects from 
Table 4

Classification Results of the CTI and WAS

\begin{tabular}{lccl}
\hline & \multicolumn{2}{c}{ Predicted Group Membership } \\
Actual Group & $\begin{array}{l}\text { Number } \\
\text { of Cases }\end{array}$ & 1 & 2 \\
\hline & & & \\
$\begin{array}{l}\text { Group 1 } \\
\text { MARRIED }\end{array}$ & 41 & 41 & 0 \\
& & $100 \%$ & $0 \%$ \\
Group 2 & 24 & 24 & 0 \\
DIVORCED & & $100 \%$ & $0 \%$ \\
\hline
\end{tabular}

Percent of "grouped" cases correctly classified: $63 \%$ 
divorced families), consistent with the "hit" rate of 63 percent since Group 1 members comprised 63 percent of the total subject pool. Essentially, the discriminant analysis predicted group membership no better than chance given the priors selected. Thus, the discriminant scores produced by the CTI and WAS do not delineate the groups to predict group membership with any significant degree of accuracy.

Hierarchical Multiple Regression Analysis of Four Predictor Variables on GCT

To establish family status (divorced versus nondivorced family of origin) as the most powerful predictor of how well individuals cope with the world on a daily basis, current age, gender, average WAS subscale score, and family status were regressed, hierarchically and in steps in that order, on the GCT $(\underline{N}=68)$. The second goal of the hierarchical multiple regression analysis was to confirm the results obtained from the discriminant analysis.

Table 5 presents the results of the regression analysis. The hypothesis that family status would provide additional predictive power over and above the demographic variables (current age and gender) and the average WAS score, excluding MW subscale, (the psychological variable) was not supported. As shown in Table 5 , family status, entered at step 4 , failed to provide significant predictive power over and above those predictor variables (current age, gender and average WAS score) already entered into the analysis $\left(\mathrm{R}^{2}=.22, \Delta \mathrm{R}_{\text {step }}^{2}=.00, \mathrm{~F}_{\Delta} \mathrm{R}_{\text {sep }}^{2}<1, \mathrm{n.s}\right.$. $)$. The regression equation 


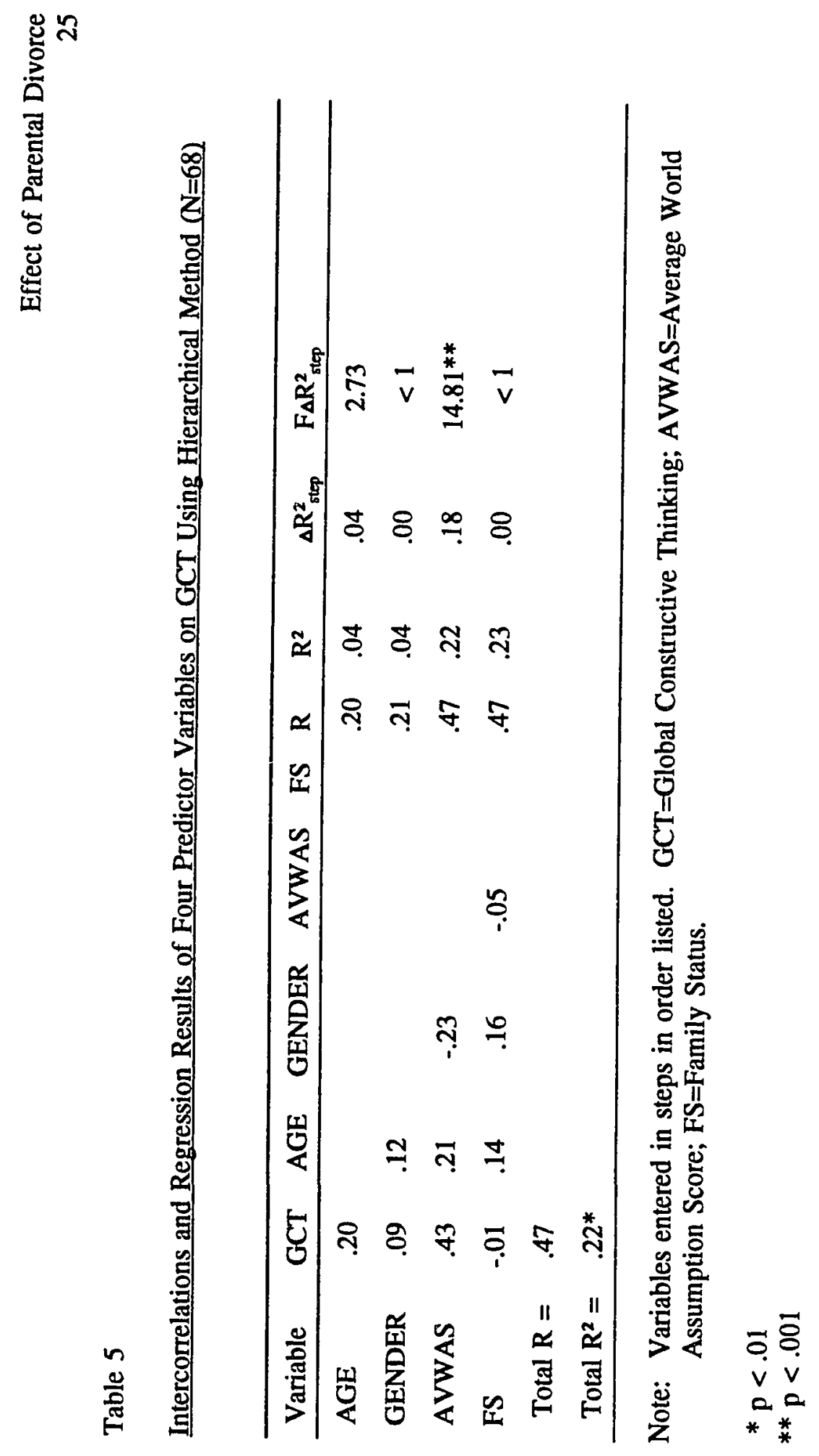


with all four predictor variables taken together proved significant $\left(R=.47, R^{2}=.22\right.$, p. $<.01)$ but only one predictor variable (AVWAS) contributed significantly to the explained variance of 22 percent. Indeed, AVWAS essentially accounted for all explained variance produced by the regression equation $\left(R^{2}=.22, \Delta R_{\text {step }}^{2}=.18\right.$, $F \Delta R_{\text {step }}^{2}=14.81$, p. $\left.<.001\right)$. Given the fact that all of the predictor variables, with the exception of family status, correlate poorly with the dependent variable GCT (see Table 5), these results are consistent and not surprising. Similar to discriminate analysis, multiple regression applies best to an analysis where the predictor variables correlate highly with the dependent variable but do not exhibit multicollinearity (Hedderson, 1991; Kachigan, 1991; Stevens, 1986).

Hierarchical Multiple Regression Analysis of Three Predictor Variables on GCT and AVWAS

To test the hypothesis that the interaction of age at the time of divorce and gender (AGED x GENDER) is most predictive of an individual's coping ability and world assumptions as compared to only gender (GENDER) or only age at the time of the divorce (AGED) given that the individual comes from a divorced family, two hierarchical multiple regression analyses were conducted on the data. One analysis regressed GENDER, AGED, and AGED $\times$ GENDER, in steps in that order, on the GCT $(N=34)$ while the second analysis regressed the same predictor variables on the average WAS score, excluding the MW subscale, $(\underline{N}=23)$. 
Tables 6 and 7 present the results of the multiple regression analyses. As indicated in each table, the results failed to support the hypothesis. AGED $\mathrm{x}$ GENDER entered at step 3 of each analysis did not add significantly to the predictive power of the regression equations following the entry of the other predictor variables GENDER and AGED (Criterion variable $=$ GCT: $R^{2}=.01, \Delta R_{\text {sep }}^{2}=.00, F_{\Delta} R_{\text {step }}^{2}=.00$, n.s.; Criterion variable $=A$ VWAS: $R^{2}=.24, \Delta R_{\text {step }}^{2}=.00, F \Delta R_{\text {step }}^{2}<1$, n.s.). Additionally, in both cases, entering the predictor variables in the analyses in the given order failed to produce a significant regression equation (Criterion variable $=C G T: R=.09, R^{2}=.00$, n.s.; Criterion variable $=$ AVWAS: $R=.48, R^{2}=.24$, n.s.). Of interest, GENDER, entered at step 1, did prove significant to the regression of the independent variables (GENDER, AGED, and AGED x GENDER) on AVWAS $\left(\mathrm{R}^{2}=.23, \Delta \mathrm{R}_{\text {step }}=.23\right.$, $\left.F \Delta R_{\text {step }}^{2}=6.29, p<.05\right)$. Based on the correlation matrices shown in Table 7 , men scored lower on the AVWAS.

The interrcorrelation matrices shown in Table 6 and Table 7 substantiate and are consistent with the results of the two regression analyses. As noted in the previous analysis, multiple regression is a statistical procedure that maximizes correlation among factors. When the predictor variables do not correlate highly with the dependent (criterion) variable and/or when the predictor variables exhibit high multicollinearity, then the size of $\mathrm{R}$ (and thus significant results) will be considerably limited. 


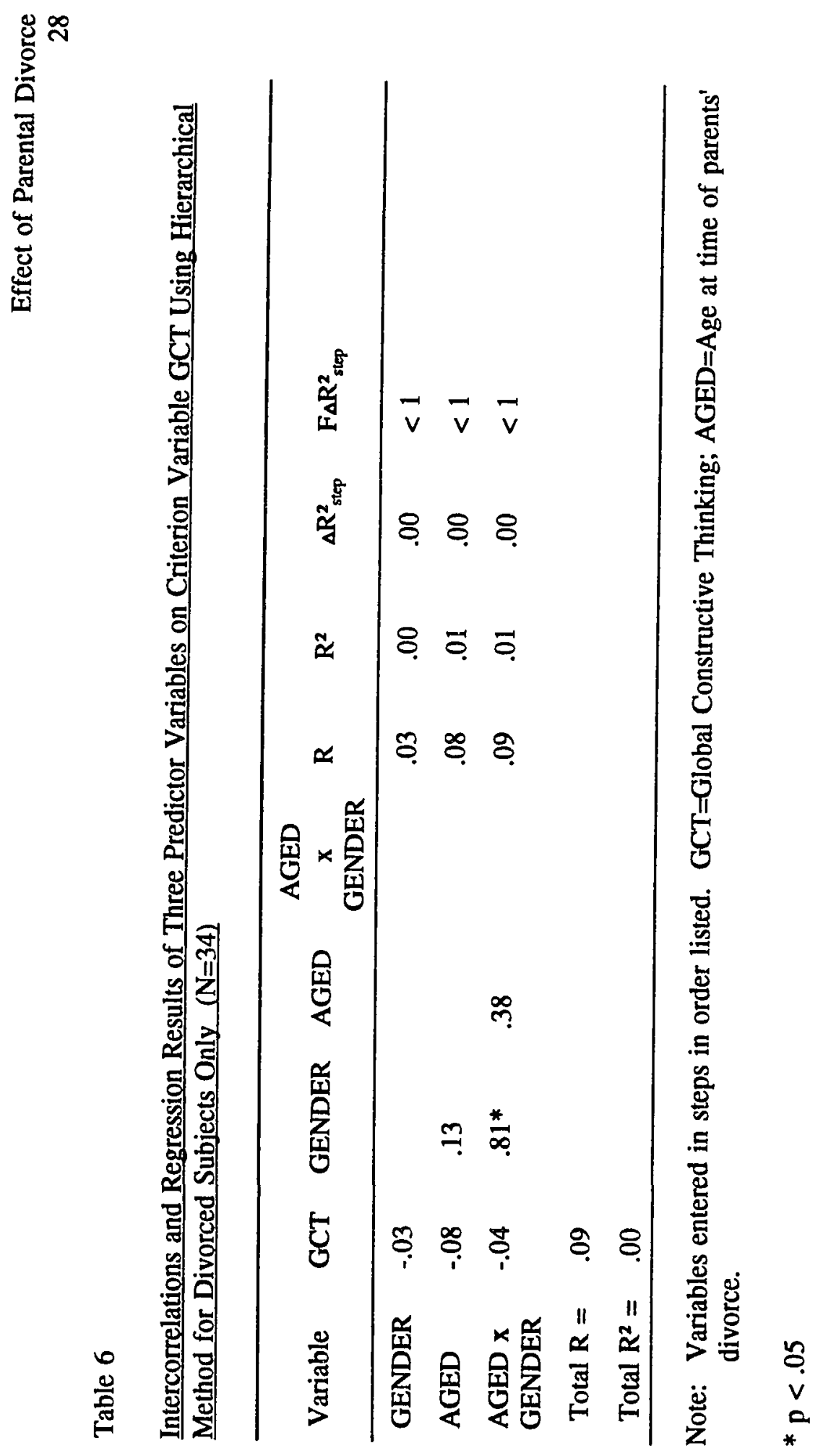




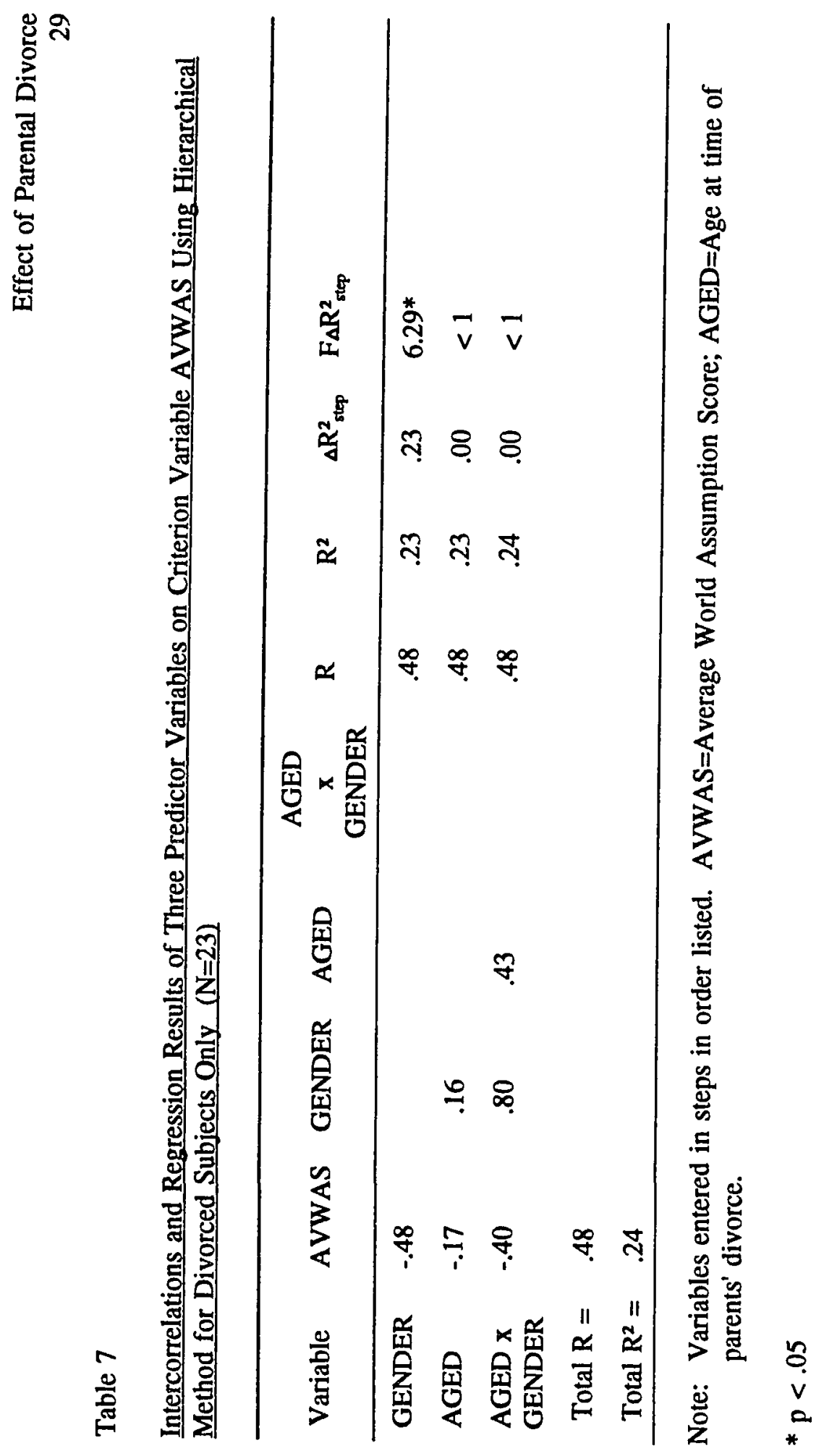




\section{Discussion}

All three hypotheses proposed in the current study failed to find support. Based on the results of the discriminant analysis, adults who experienced divorce as children do not, as a group, possess coping strategies and worldviews distinct from the group of adults who did not experience divorce as children.

The findings of the multiple regression analysis of current age, gender, average WAS score, and family status on constructive thinking confirm the results of the discriminant analysis: membership in family status groups cannot be distinguished on the basis of the CTI and WAS scores, and alternately, family status does not explain the coping strategies adopted by adults. In other words, whether individuals come from an intact family or one where their parents divorced does not place them in a unique group on the basis of their ability to cope with the world or in the way they see the world, nor does their family status predict whether they will cope successfully with the world. What the resuits of the present analysis do suggest is that an individual's worldview is the most important factor in predicting coping skills.

Finally, the multiple regression analysis of gender, age at the time of divorce, and the interaction of gender and age at the time of divorce on constructive thinking and world assumptions, failed to support the hypothesized results: the interaction of gender and age at the time of divorce did not prove to be significantly predictive of coping strategies and assumptive worlds among adults who came from a divorced 
family of origin. These results indicate that the combined effects of gender and age at the time of divorce exert little influence on how an individual raised in a divorced environment develops coping styles or views about the world. That is, being of a certain gender or of a certain age when the intact family breaks apart, taken together, does not predict the kinds of coping strategies or worldviews an individual will eventually adopt.

However, although not anticipated, the present research confirms one of the two robust findings of previous research: among children of divorce, gender does influence world views. In particular, males from divorced families do not perceive the world to be as good or kind a place as do women from divorced families nor do they consider themselves to be as upstanding and or deserving of good fortune as do women. For example, males from divorced families were more likely to perceive the world as basically evil, human nature as intrinsically bad, and other people as fundamentally unkind and unfriendly. Additionally, males from divorced families were more likely to feel that they were unlucky people, unable to prevent personal misfortune, and less satisfied with themselves and their character.

Wallerstein and colleagues (Wallerstein \& Blakeslee, 1989; Wallerstein \& Kelly, 1980) warn that divorce engenders changes that become "deeply embedded in each person's world view" (Wallerstein \& Blakeslee, 1989) according to the evidence gained from their studies that "a brief trauma in childhood could affect an individual's 
long term attitudes" (Wallerstein \& Blakeslee, 1989). Yet the literature offers inconsistent and contradictory findings about the nature of those fundamental changes (Cantor \& Drake, 1983; Emery, 1988; Levin, 1989). A good deal of the confusion in the literature results from flawed methodology, in particular the failure to use a valid and reliable measurement tool that assesses enduring, long-term effects (as opposed to immediate, crisis generated effects) where the confounding of the temporal variables (current age, age at the time of divorce and time since the divorce occurred) is minimized (Cantor \& Drake, 1983; Emery, 1988; Levin, 1989). Few longitudinal studies exist that assess adult adjustment based on having experienced the dissolution of their parents' marriage (Emery, 1988).

The current investigation, by addressing some of the more serious methodological weaknesses of previous research, attempted to provide some insight into how and if the divorce experience permanently impacts those it touches. By obtaining subjects from an adult sample, the impact of all time related factors became less consequential due to the passage of time.

Most importantly, the CTI and WAS represent valid and reliable constructs especially suited to assessing overall orientation and adjustment to life. Taken together, these two measures provide a vehicle for assessing the character of an individual's fundamental and basic approach to the world coupled with a look at the automatic thought processes occurring as a result of that individual's orientation to life 
and experience with the world. Indeed, a serendipitous finding in the current investigation was that the WAS predicted styles of coping (GCT) more powerfully than any of the other factors (current age, gender, and family status).

Given the information supplied by the CTI and WAS and given the results of the analyses conducted in the current research, several conclusions can be drawn that question the Wallerstein, et al. (Wallerstein \& Blakeslee, 1989; Wallerstein \& Kelly, 1980) findings: (1) As a group, adults whose parents' divorced, are indistinguishable from the group of adults whose parents remained married by virtue of their coping abilities or worldviews. Consistent with the above, whether an individual comes from a divorced family of origin or an intact family offers little information about how successful that individual will be in coping with life; (2) Among the group whose parents divorced, practical intelligence and worldview cannot be predicted on the basis of the combined effects of gender and age at the time of divorce. As is the case in any study presenting results in support of the null hypothesis, questions remain about whether differences truly exist but remain undetected because of methodological or statistical artifacts or limitations. The only way to answer the question is to replicate the current study with a different population.

However, assuming that the results are valid, one possible explanation for the finding of no significant differences between children of divorce and children of nondivorce on these particular measures exists. Individuals who become students at a 
major state university must possess enough "practical intelligence" and adaptive views about the world to allow them to succeed, regardless or perhaps even despite the particulars of their families of origin. In other words, college students are more alike than different in their coping styles and beliefs about the world. If this study were replicated in the general population, differences might be found between adults whose parents divorced when they were children compared to adults whose family remained intact.

While it is possible that the sample used in this study was not representative of the general population, the demographics of this study do not support such a contention. Hetherington, et al. (1989) estimated that over the next several decades between $40 \%$ to $50 \%$ of children would come from divorced households while Levin (1989) suggested an estimate of between $33 \%$ and $44 \%$. The demographics of the present study fall well within those estimates with $34 \%$ of the sample coming from divorced families and $66 \%$ coming from intact homes. Although there are no statistics available on the number of students attending college who come from divorced families, the best estimate comes from the Higher Education Research Institute at the University of California at Los Angeles. According to their annual survey of more than 200,000 college freshman at four-year institutions, in 1992 more than $25 \%$ of those entering freshman come from divorced homes (Cage, 1993). Considering the fact that the Institute's annual survey is nearly two years old and includes only first 
time and full-time freshman, thus excluding all transferring, re-entry, upper class, and part-time students, it would be reasonable to assume that the $25 \%$ figure is indeed conversative and would likely be much higher.

Putting aside possible explanations based on the kind of sample used and again assuming the findings to be valid, the present investigation suggests at least three implications. First, the findings suggest that the experience of having coming from a divorced family poses no greâtêr threat or offers no greater advantage to the development of coping skills or the alteration of basic world assumptions than does the experience of having come from an intact family. Moreover, the findings caution against the tendency to dichotomize children of divorce "as either fragile or magnificently resilient" (Emery, 1988, p. 9) or to assume that "the long term outcome of divorce is inevitably pathological" (Emery, 1988, p. 9).

This implication points to a bias in the literature. The literature on divorce related effects tends to view the intact family as the standard against which all other family systems are to be judged. Said another way, the intact family stands as a model of the psychologically healthy family environment. In contrast, the divorced family and subsequent family structures continue to be viewed as more developmentally problematic for children. While Wallerstein, et al. (Wallerstein \& Blakeslee, 1989) outlines the psychological tasks to be undertaken by children of divorce in addition to normal developmental tasks, no such list exists for children 
living and growing up in intact homes. There seems to be an implicit assumption, indeed almost an illusion, that children living in intact families go about their development tasks undisturbed by any other psychological concerns.

The findings of this study seem to dispel this myth by suggesting that each group of children faces challenges beyond those of normal development and that those additional tasks differ more in kind than quantity or degree. For example, while a child of divorce learns how to live in two households, a child from an intact family learns how to share his room with a younger sibling. Yet, underlying the situationspecific challenges may be the same fundamental lessons of life.

A second implication brought forth by the current investigation concerns how individuals incorporate traumatic events into their worldview. Janoff-Bulman and Timko (1987) conceive of world assumpiions as higher order schemas or cognitive concepts that exist, according to Epstein's (1980) cognitive-experiential self-theory, as a major postulates in an individual's theory of reality. An example of a major postulate, or higher level schema, might be "I am a worthy person" while a minor postulate, or lower level schema, might be "I am good tennis player" followed by a slightly higher order "I am a good athlete" (Janoff-Bulman \& Timko, 1987, p. 136). These higher order postulates form the basis of "our most abstract, generalized theories about the nature of the world and ourselves" (Janoff-Bulman \& Timko, p. 1987). Drawing a parallel between the characteristics of world assumptions and cognitive 
knowledge structures (schemas), Janoff-Bulman and Timko (1987) cite two major conclusions from schema research: (1) people look for consistency and coherence in their world assumptions; and (2) world assumptions are resistant to change. Support for their position is found in previous research regarding models of schematic change (Crocker, Fiske, \& Taylor, 1981). According to Janoff-Bulman (1989; 1992; JanoffBulman \& Frieze, 1983; Janoff-Bulman \& Timko, 1987), traumatic events pose a serious threat to our world assumptions because "our conceptual system . . is simply unable to incorporate the data of the traumatic experience; the new data do not fit" (Janoff-Bulman \& Timko, 1987, p. 141).

In response to serious life events, people either alter their assumptions about the world so that the data fit (accommodation) or they distort the data so that their worldviews remain intact (assimilation; see Piaget). Several studies indicate that people indeed alter their basic beliefs about the world following a major crisis in their lives despite the resistance to do so (Janoff-Bulman 1989; 1992; Lehman, Wortman, \& Williams, 1987; Schwartzberg \& Janoff-Bulman, 1991), while other studies suggest that people change their perception of the data to accommodate and protect their world assumptions (Lerner, 1970; Hafer \& Olson, 1989; Kleinke \& Meyer, 1990; Kristiansen \& Giulietti, 1990). Theory abounds regarding the processes that allow people to maintain their assumptive worlds in the face of incongruent information, for instance, by denial (Horowitz, 1983; Janoff-Bulman \& Timko, 1987; Lazarus, 1983), by 
exerting control and engaging in preventative behaviors (Janoff-Bulman \& Frieze, 1983; Taylor, 1983), by minimizing the victimization (Taylor, Wood \& Lichtman, 1983), and by searching for meaning (Horowitz, 1979; Janoff-Bulman \& Timko, 1983; Taylor, 1983; Taylor, Wood \& Lichtman, 1983).

The findings of the current study imply that in response to the trauma of divorce children do not alter their assumptive worlds but instead change the experience to match their worldview. Thus, the present investigation is another example of an instance where world assumptions, although challenged, resist change. Unfortunately, the current study offers no information about the processes or mechanisms by which children of divorce make the reality of the divorce experience congruent with their view of the world.

The third and final implication suggested by the current research addresses the issue of when and if there exists a better time to divorce considering the long-term adjustment of the children, a question frequently asked by parents considering a divorce (Wallerstein \& Kelly, 1980) and whether one gender is at more risk than the other. The findings here indicate that in the long-term gender, age at the time of divorce and the combined effect of gender and age at the time of divorce do not represent significant factors affecting the development of coping mechanisms or the alteration of basic world assumptions. In other words, in terms of the overall adjustment and life orientation of children, there is no "perfect" time to divorce given 
certain ages and the specific gender of children.

This implication is consistent with previous research that suggests factors other than age and gender exert the most influence on long-term divorced related adjustment by mitigating the negative effects, such as continuing participation and involvement by both parents in the child's life (Cantor \& Drake, 1983; Hodges, 1991; Wallerstein \& Blakeslee, 1989;), particular patterns of family interactions in the post-divorce environment (Emery, 1988; Hetherington, 1979; Hetherington, Stanley-Hagan, \& Anderson, 1989; Oppawsky, 1989; 1991; Warshak, 1986), the quality of parenting (Hodges, 1991; Warshak, 1986), economic factors (Hodges, 1991), and the lack of conflict (Hodges, 1991; Oppawsky, 1991; Wallerstein \& Blakeslee, 1989).

The implications of this investigation point to three areas of future research. First, research needs to be conducted on the critical factors in childhood, regardless of the configuration of the family system, that produce constructive thinkers so that the standard becomes the important lessons (or processes) that need to be learned rather than the structure of the family system itself. Secondly, research designed to discover the mechanisms by which children of divorce keep their assumptive world intact despite the crisis of the divorce experience would provide information useful to both family psychologists and social psychologists. Finally, research needs to focus on categorizing and ranking the variables most critical in mitigating the negative effects and maximizing the positive aspects of the divorce experience on children. 


\section{References}

Cantor, D., \& Drake, E. (1983). Divorced parents and their children. New York: Springer Publishing Company.

Cage, M. (1993, June 30). The post-baby boomers arrive on campus: college officials scoff at popular stereotypes, but they agree today's students are different. Chronicle of Higher Education, pp. 27-29.

Clarke-Stewart, A., \& Friedman, S. (1987). Child development: infancy through adolescence. New York: John Wiley \& Sons.

Crocker, J., Fiske, S., \& Taylor, S. (1981). Schematic bases of belief change. In E. Higgins, C. Herman, \& M. Zanna (Eds.), Social cognition (pp. 197-226). Hillsdale, NJ: Lawrence Erlbaum Associates.

Emery, R. (1988). Marriage, divorce, and children's adjustment. Newbury Park, CA: Sage Publications, Inc.

Epstein, S. (1980). The self-concept: a review and the proposal of an integrated theory of personality. In E. Staub (Ed.), Personality: basic aspects and current research (pp. 81-128). Englewood Cliff, NJ: Prentice-Hall, Inc.

Epstein, S. (1983). The unconscious, the preconscious, and the self-concept. In J. Suls and A. Greenwald (Eds.), Psychological perspectives on the self (Vol. 2, pp. 219-247). Hillsdale, NJ: Lawrence Erlbaum Associates. 
Effect of Parental Divorce

Epstein, S. (1990). Cognitive-experiential self-theory. In L. Pervin (Ed.), Handbook of personality: theory and research (pp. 165-182). New York: Guilford Press. Epstein, S. (1992a). Constructive thinking and mental and physical well-being. In L. Montada \& S. Filipp (Eds.), Life crisis and experiences of loss in adulthood (pp. 385-409). Hillsdale, NJ: Lawrence Erlbaum Associates.

Epstein, S. (1992b). Coping ability, negative self-evaluation, and overgeneralization: experiment and theory. Łournal of Personality and Social Psychology, 62, 826-836.

Epstein, S., \& Katz, L. (1992). Coping ability, stress, productive load, and symptoms. Joumal of Personality and Social Psychology, 62, 813-825.

Epstein, S., Lipson, A., Holstein, C., \& Huh, E. (1992). Irrational reactions to negative outcomes: evidence for two conceptual systems. Journal of Personality and Social Psychology, 62, 328-339.

Epstein, S., \& Meier, P. (1989). Constructive thinking: a broad coping variable with specific components. Journal of Personality and Social Psychology, 57, 332-350.

Farmer, S. (1989). Effects of parental separation and divorce on children. In G. Weeks (Ed.), Treating couples (pp. 258-286). New York: Brunner/Mazel Publishers. 
Feist, G., Bodner, T., Jacobs, J., Miles, M., \& Tan, V. (1994). Integrating top down and bottom-up structural models of subjective well-being: a longitudinal investigation. Manuscript submitted for publication.

Hafer, C., \& Olson, J. (1989). Beliefs in a just world and reactions to personal deprivation. Journal of Personality, 57, 799-823.

Heath, P., \& MacKinnon, C. (1988). Factors related to social competence of children in single-parent families. Journal of Divorce, 11, 49-67.

Hedderson, J. (1991). SPSS/PC+ made simple. Belmont, CA: Wadsworth, Inc.

Hetherington, E. (1979). Divorce: a child's perspective. American Psychologist, 34 , 851-858.

Hetherington, E., Stanley-Hagan, M., \& Anderson, E. (1989). Marital transitions. American Psychologist, 44, 303-312.

Hodges, W. (1991). Interventions for children of divorce: custody, access, and psychotherapy. New York: John Wiley \& Sons.

Horowitz, M. (1979). Psychological response to serious life events. In V. Hamilton \& D. Warburton (Eds.), Human siress and cognition (pp. 235-263). New York: Wiley \& Sons.

Horowitz, M. (1983). Psychological response to serious life events. In S. Breznitz (Ed.), The denial of stress (pp. 129-159). New York: International Universities Press, Inc. 
Hurley, J. (1989). Constructive thinking and elevated ratings of self in interpersonal groups. The Journal of Psychology, 124, 563-573.

Janoff-Bulman, R. (1989). Assumptive worlds and the stress of traumatic events: applications of the schema construct. Social Cognition, Z(2), 113-136.

Janoff-Bulman, R. (1992). Shattered Assumptions. New York: Free Press.

Janoff-Bulman, R., \& Frieze, I. (1983). A theoretical perspective for understanding reactions to victimization. Journal of Social Issues, 39, 1-17.

Janoff-Bulman, R., \& Timko, C. (1987). Coping with traumatic life events--the role of denial in light of people's assumptive worlds. In C. Snyder \& C. Ford (Eds.), Coping with negative life events (pp. 135-159). New York: Plenum Press.

Katz, L., \& Epstein, S. (1991). Constructive thinking and coping with laboratory induced stress. Journal of Personality and Social Psychology, 61, 789-800.

Kachigan, S. (1991). Multivariate statistical analysis. New York: Radius Press.

Kleinke, C., \& Meyer, C. (1990). Evaluation of rape victim by men and women with high and low belief in a just world. Psychology of Women Quarterly, 14 , 343-353.

Kristiansen, C., \& Giulietti, R. (1990). Perceptions of Wife Abuse. Psychology of Women Quarterly, 14, 177-189. 
Kurdek, L., \& Berg, B. (1987). Children's beliefs about parental divorce scale: psychometric characteristics and concurrent validity. Journal of Consulting and Clinical Psychology, 55, 712-718.

Lazarus, R. (1983). The costs and benefits of denial. In S. Breznitz (Ed.), The denial of stress (pp. 1-30). New York: International Universities Press, Inc. Lehman, D., Wortman, C., \& Williams, A. (1987). Long-term effects of losing a spouse or child in a motor vehicle crash. Journal of Personality and Social Psychology, 52, 218-231.

Lerner, M. (1970). The desire for justice and reactions to victims. In J. Maccaulay \& L. Berkowitz (Eds.), Altruism and helping behavior (pp. 205229). New York: Academic Press.

Lerner, M. (1980). The belief in a just world. New York: Plenum Press.

Levin, M. (1989). Sequelae to marital disruption. Journal of Divorce, 12, 25-81.

Oppawsky, J. (1989). Family dysfunctional patterns during divorce from the view of the children. Journal of Divorce and Remarriage, 16, 291-304.

Oppawsky, J. (1991). The effects of parental divorce on children in west germany: emphasis from the view of the children. Journal of Divorce and Remarriage, 16, 291-304. 
Schwartzberg, S., \& Janoff-Bulman, R. (1991). Grief and the search for meaning: exploring the assumptive worlds of bereaved college students. Journal of Social and Clinical Psychology, 10(3), 270-288.

Stevens, J. (1986). Applied multivariate statistics for the social sciences. Hillsdale, NJ: Lawrence Erlbaum Associates, Publishers.

Spigelman, G., \& Spigelman, A. (1991). Parental divorce as a factor in children's perception of human relationships: an analysis of human movement responses in the roschach test. Scandinavian Journal of Psychology, 23, 167-174.

Taylor, S. (1983). Adjustment to threatening events: a theory of cognitive adaptation. American Psychologist, $\underline{38}, 1161-1173$.

Taylor, S., Wood, J., \& Lichtman, R. (1983). It could be worse: selective evaluation as a response to victimization. Iournal of Social Issues, 39, 19-40.

Wallerstein, J. \& Kelly, J. (1980). Surviving the breakup. New York: Basic Books.

Wallerstein, J., \& Blakeslee, S. (1989). Second chances: men, women, and children a decade after divorce. New York: Tichnor \& Fields.

Warshak, R. (1986). Father-custody and child development: a review and analysis of psychological research. Behavioral sciences \& the law, 4, 185-202. 
Effect of Parental Divorce

46

Appendices 
Appendix A

\section{Biographical Questionnaire}

To assure confidentiality we need an ID code that is yours and yours only. The best way to create such a code is to use the first 3 letters of your mother's MADEN name and the 6 digits of your birthday. For example, if your mother's maiden name were Johnson and you were born January 23, 1969 your code would be JOH012369. Please put your secret code on the line below. Use this ID for all questionnaires.

Code ID

Freshman

Grad Student

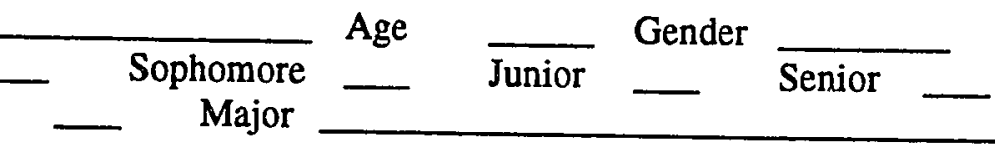

Marital Status: Single Married Divorced

Occupation of Mother

Occupation of Father

Parent's Marital Status: Married Divorced

If divorced, how old were you when they were divorced

Ethnic descent:

$\begin{array}{llll}\text { African-American } & & \text { Asian-American } \\ \text { European-American } & - & \begin{array}{l}\text { Indian/Pakistani } \\ \text { Latino-American }\end{array} \text { Mexican-American } \\ \text { Middle-Eastern } & - & \begin{array}{l}\text { Native American } \\ \text { Pacific Islander }\end{array} \\ \text { Other } & - & \begin{array}{l}\text { Pilipino/Filipino } \\ \end{array}\end{array}$

Are the majority of your friends of the same ethnic group? Yes

How many generations ago did your ancestors come to the US?

Primary language spoken at home

Religious Background (of family of origin):

Catholic

Muslim Protestant Atheist/None Jewish Other Buddhist

How important to you is your religious affiliation:

Not at all important

Somewhat unimportant

Neutral

Somewhat important 
Effect of Parental Divorce

Very important

In the last year, have you gone through any major life event(s) or stressor(s)? If so, please list: 
Appendix B

\section{Constructive Thinking Inventory}

The following are some statements on feelings, beliefs, and behavior. Score " 1 " if the statement is definitely false; " 5 " if it is definitely true. A rating of "2" will indicate that the statement is mainly false; a rating of " 4 " that it is mainly true. Use "3" only if you cannot decide if the item is mainly true or false.

Be honest, but do not spend too much time over any one statement. First impressions are as accurate as any. Please write all of your numerical responses on the line in front of each question.

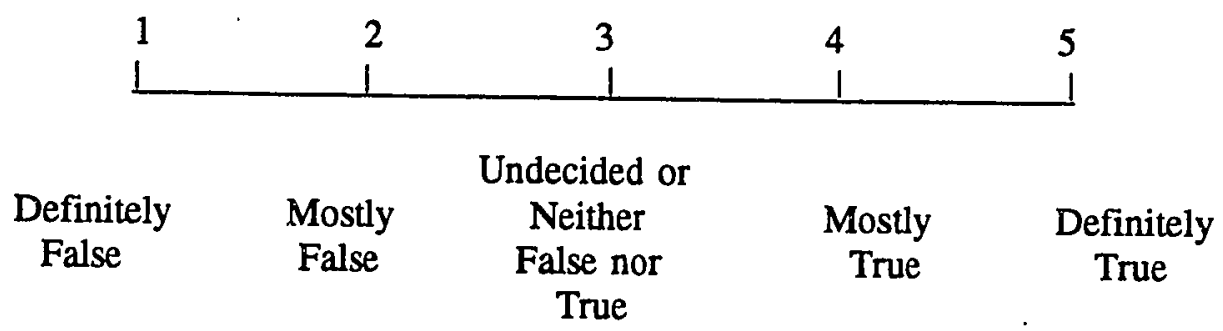

1. I worry a great deal about what other people think of me.

2. I am the kind of person who takes action rather than just thinks or complains about a situation.

3. Most people regard me as a tolerant and forgiving person.

4. I have found that talking about successes that I am looking forward to can keep them from happening.

5. When I have that someone I love loves me, it has made me feel like a wonderful person and that I can accomplish whatever I want.

6. I have learned from bitter experience that most people are not trustworthy.

7. When I am faced with a difficult task, I think encouraging thoughts that help me to do my best.

8. I have washed my hands before eating at least once in the past month. 
9. If I said something foolish when I spoke up in a group, I would chalk it up to experience and not worry about it.

10. I often avoid facing problems.

11. I usually feel that it is acceptable for me to do well in some things and not so well in others.

12. When something bad happens to me, I feel that more bad things are likely to follow.

13. I think everyone should love their parents.

14. If I do poorly on an important test, I feel like a total failure and that I won't go very far in life.

15. I get so distressed when I notice that I am doing poorly in something that it makes it worse.

16. The slightest indication of disapproval gets me upset.

17. If I have something unpleasant to do, I try to make the best of it by thinking in positive terms.

18. When someone I know is rejected by a person they love, I feel they are inadequate and will never be able to accomplish anything.

19. I have never seen anyone with blue eyes.

20. I believe that some people can make me aware of them just by thinking about me.

21. I don't get very distressed over the mistakes of others, but try to deal with them in a constructive way.

22. If I do well on an important test, I feel like a total success and that I will go very far in life.

23. When I have to be in an unpleasant or boring situation for a while, I keep watching the clock and wishing I were somewhere else. 
24. I think about how I will deal with threatening events ahead of time, but I don't worry needlessly.

25. I avoid challenges because it hurts too much when I fail.

26. There are basically two kinds of people in this world, good and bad.

27. I believe if I think terrible thoughts about someone, it can affect that person's well-being.

28. When people judge me unfavorably, I tend to think they are right.

29. When someone I know is loved by a person they love, I feel that they are a wonderful person and can accomplish whatever they want to.

30. When something unfortunate happens to me, it reminds me of all the other things wrong in my life, which adds to my unhappiness.

31. It bothers me when anyone doesn't like me.

32. I look at challenges not as something to fear, but as an opportunity to test myself and learn.

33. I think there are many wrong ways, but only one right way, to do almost anything.

34. I do not believe in any superstitions.

35. I spend much more time mentally rehearsing my failures than remembering my successes.

36. I believe that most birds can run faster than they can fly.

37. I someone I know were accepted at an important job interview, I would think that he or she would always be able to get a good job.

38. I believe that most people are only interested in themselves.

39. I don't let little things bother me. 
40. If I were rejected at an important job interview, I would feel very low and think I would never be able to get a good job.

41. I believe that in order to have a good relationship, you have to work on it.

42. When I am faced with a new situation, I tend to think the worst possible outcome will happen.

43. I believe in not taking any chances on Friday the 13th.

44. I believe that people can accomplish anything they want if they have enough willpower.

45. I feel that people who wear glasses usually can see better without their glasses.

46. I tend to dwell more on pleasant than unpleasant incidents from the past.

47. When unpleasant things happen to me, I don't let them prey on my mind.

48. When faced with upcoming unpleasant events, I usually carefully think through how I will deal with them.

49. If I do very poorly on a test, I realize it is only a single test, and it doesn't make me feel generally incompetent.

50. I tend to classify people as either for me or against me.

51. It would not bother me in the least if a black cat crossed my path and I walked under a ladder on the same day.

52. If I were accepted at an important job interview, I would feel very good and think that I would always be able to get a good job.

53. My mind sometimes drifts to unpleasant events from the past.

54. I tend to take things personally.

55. Although women sometimes wear pants, they do not wear them, on the average, as often as men. 
56. When doing unpleasant chores, I make the best of it by thinking pleasant or interesting thoughts.

57. When faced with a large amount of work to complete, I tell myself I can never get it done, and feel like giving up.

58. I try to accept people as they are without judging them.

59. I sometimes think that if I want something to happen too badly, it will keep it from happening.

60. I have very definite ideas about how things should be done, and I get distressed when they are not done that way.

61. It is so distressing to me to try hard and fail, that I rarely make an all-out effort to do my best.

62. When someone I love has rejected me, it has made me feel inadequate and that I will never be able to accomplish anything.

63. I am very sensitive to being made fun of.

64. When something good happens to me, I believe it is likely to be balanced by something bad. 


\section{Appendix C}

\section{World Assumptions Scale}

Using the scale below, please select the number that indicates how much you agree or disagree with each statement. Please answer honestly. Thanks.

$$
\begin{aligned}
& 1=\text { strongly disagree } \\
& 2=\text { moderately disagree } \\
& 3=\text { slightly disagree } \\
& 4=\text { slightly agree } \\
& 5=\text { moderately agree } \\
& 6=\text { strongly agree }
\end{aligned}
$$

- 1. Misfortune is least likely to strike worthy, decent people.

2. People are naturally unfriendly and unkind.

3. Bad events are distributed to people at random.

4. Human nature is basically good.

5. The good things that happen in this world far outnumber the bad.

6. The course of our lives is largely determined by chance.

- 7. Generally, people deserve what they get in this world.

- 8. I often think I am no good at all.

- 9. There is more good than evil in the world.

- 10. I am basically a lucky person.

- 11. People's misfortunes result from mistakes they have made.

- 12. People don't really care what happens to the next person.

- 13. I usually behave in ways that are likely to maximize good results for me. 
- 14. People will experience good fortune if they themselves are good.

- 15. Life is too full of uncertainties that are determined by chance.

- 16. When I think about it, I consider myself very lucky. 17. I almost always make an effort to prevent bad things from happening to
me.

18. I have a low opinion of myself.

19. By and large, good people get what they deserve in this world.

20. Through our actions we can prevent bad things from happening to us.

21. Looking at my life, I realize that chance events have worked out well for me.

22. If people took preventive actions, most misfortune could be avoided.

23. I take the actions necessary to protect myself against misfortune.

24. In general, life is mostly a gamble.

25. The world is a good place.

26. People are basically kind and helpful.

- 27. I usually behave so as to bring about the greatest good for me.

- 28. I am very satisfied with the kind of person I am.

- 29. When bad things happen, it is typically because people have not taken the necessary actions to protect themselves.

30. If you look closely enough, you will see that the world is full of goodness.

31. I have reason to be ashamed of my personal character. 
Effect of Parental Divorce 56

- 32. I am luckier than most people. 